\title{
Flexural strength of walls made of hollow core concrete brick using various notch models as the interlocking device
}

\author{
Nanang Gunawan Wariyatno ${ }^{1, *}$, Yanuar Haryanto ${ }^{1}$, and Sumiyanto ${ }^{1}$ \\ ${ }^{1}$ Jenderal Soedirman University, Department of Civil Engineering, Jl. Mayjend. Sungkono KM 5, \\ Blater, Purbalingga, 53371, Indonesia
}

\begin{abstract}
The effectiveness of hollow core concrete bricks made of sand and stone ash mixture as alternative substitute materials has been previously studied, considering their weight, load capacity, construction time, and cost. To obtain an optimal notch model as the interlocking device, this further study is conducted. The previous notch model is in the shape of a 2-cm trapezoid and is varied here to consider a $2-\mathrm{cm}$ rectangular notch model and 3- and 3.5-cm trapezoid notch models. The ratio of sand to stone ash in the mixture is $25: 75$. The wall specimen refers to the previous studies, which investigated specimens with sizes of $90 \times 45 \mathrm{~cm}^{2}$ under out-of-plane loading and $60 \times 60 \mathrm{~cm}^{2}$ under in-plane loading. We found that the $2-\mathrm{cm}$ rectangular notch model is optimal as the interlocking device of the wall made of hollow core concrete bricks, with a flexural strength under out-of-plane loading of $212.29 \mathrm{kN} / \mathrm{m}^{2}$ and a flexural strength under in-plane loading of $330.92 \mathrm{kN} / \mathrm{m}^{2}$, representing increases of 14.63 and $175.77 \%$, respectively, compared to the values obtained in previous studies. The failure or collapse initially starts from the material parts and then continues to the connection ones.
\end{abstract}

\section{Introduction}

Indonesia is a country with high consumption of resources due to the continuously increasing population and economic growth. The Central Bureau of Statistics [1] reports that the total estimated value of completed constructions based on working types in 2015 reached more than Rp. 635 trillion. According to news recently released by PT Semen Indonesia (Persero) Tbk on 31 October 2016, it is estimated that the national cement consumption in 2017 will reach 68 million tonne, representing a growth of 8.04\% compared to the consumption during the previous year of 2016, when it reached only 62.94 million tonne [2]. Red bricks are commonly used for walls of either simple house buildings or reinforced concrete building structures in developing countries and earthquake-prone countries [3], such as Indonesia [4, 5]. However, considering environmental conservation and natural resources, a new brick type is immediately required to replace the red one. Such efforts have been conducted by examining the effectiveness of hollow core concrete bricks

\footnotetext{
${ }^{*}$ Corresponding author: nanang_g@yahoo.com
} 
made of sand and stone ash mixture as an alternative substitute material for use in walls by reviewing their weight, load capacity, installation time, and cost. Further studies are required to obtain an optimum notch model of the interlocking device by considering the flexural strength and wall failure mode parameters of hollow core concrete bricks.

An alternative material development for walls has been conducted by Pang et al. [6], who investigated a wall with a size of 1,500 $\times 2,000 \times 240 \mathrm{~mm}^{3}$ made of sand, soil, and lime mixture in a certain ratio with various hollow openings. After the first stage of testing, the wall was coated with reinforcing steel-fibre mortar on both sides and then retested. It is known that increasing the amount of lime in the mixture may improve the wall strength. The hollow opening does not influence the wall-supporting capacity, but the reinforcing steel fibre mortar may effectively improve the wall-supporting capacity. All wall types experience collapse due to losing layers of the reinforcing steel fibre mortar as a result of cohesive failure, in which layers of reinforcing steel fibre mortar suffer only slightly from cracks and damages. This is caused by the damage to the inner wall occurring during the first testing stage.

In response to the need for low-level buildings in rural areas of China, Cao et al. [7] developed Recycled Concrete Bricks (RCBs) with a size of $53 \times 115 \times 260 \mathrm{~mm}^{3}$ using recycled aggregates obtained from construction waste of buildings destroyed in Beijing, which are further processed to produce fine and coarse aggregate. Monotonic testing was performed against an RCB wall with a size of $780 \times 260 \times 390 \mathrm{~mm}^{3}$, while cyclic testing was performed against an RCB wall with a size of $260 \times 115 \times 53 \mathrm{~mm}^{3}$ equipped with vertical reinforcing steel. It was found that the RCB wall failure pattern was similar to the red brick wall failure pattern for axial loading pressure. In an RCB wall with vertical reinforcement, the hidden column elements effectively restrict the occurrence of deformations and cracks, so the RCB wall may become more ductile, being supported by a simple and relatively low-cost construction, and may therefore become a good alternative choice for low-level seismic building design in rural areas.

Wariyatno et al. [8] conducted a study that aimed to determine the effectiveness of hollow core concrete brick as an alternative wall material substitute due to the weight, load capacity, installation time, and cost. The specimens consisted of two wall types with sizes of $90 \times 45$ and $60 \times 60 \mathrm{~cm}^{2}$. The results showed that the hollow core concrete brick wall had a weight of $237.61 \mathrm{~kg} / \mathrm{m}^{2}$, which was lighter than the red brick wall, whose weight was $270.45 \mathrm{~kg} / \mathrm{m}^{2}$. However, it was still heavier than the light brick wall, whose weight was only $193.54 \mathrm{~kg} / \mathrm{m}^{2}$. The load capacity of the hollow core concrete brick wall was $4.17 \mathrm{kN}$, while those of the red brick wall and light brick wall were 5.55 and $2.87 \mathrm{kN}$ respectively. The hollow brick wall had a construction time of $52 \mathrm{~min} / \mathrm{m}^{2}$ with a cost of only $\mathrm{Rp}$. $187.400 / \mathrm{m}^{2}$, so it could be constructed much faster and more cheaply than the red brick wall, which had a construction time is $182 \mathrm{~min} / \mathrm{m}^{2}$ and a cost of Rp. $302.400 / \mathrm{m}^{2}$, and the light brick wall, which had a construction time is $140 \mathrm{~min} / \mathrm{m}^{2}$ and a cost of Rp. $279.000 / \mathrm{m}^{2}$. The effectiveness of the hollow core concrete brick is obviously high, but it still has some weaknesses in the connection part.

\section{Methodology}

\subsection{Equipment and materials}

The equipment used in this study included ovens, scales, concrete mixer machines, hollow core concrete brick mould (Figure 1), and a Universal Testing Machine (UTM). The materials used were as follows: sand, stone dust, cement, water, and PVC pipes. 


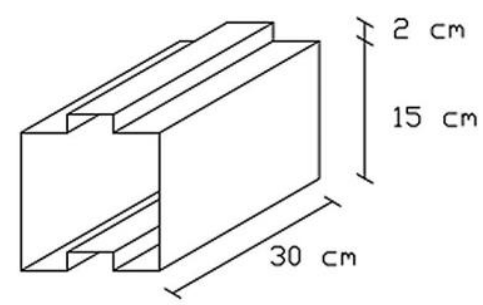

(a)

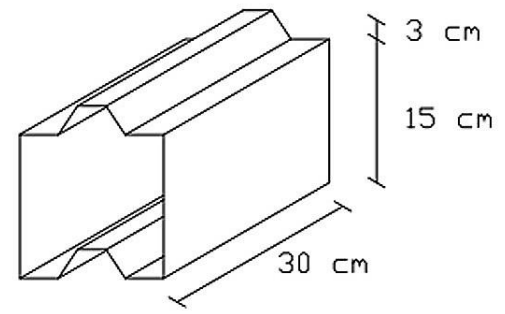

(b)

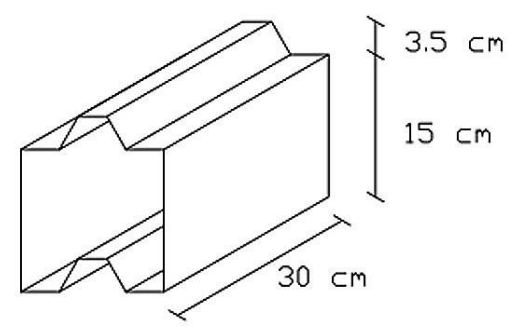

(c)

Fig. 1. Hollow core concrete brick mould; (a) 2-cm square notch, (b) 3-cm trapezoid notch, c) $3.5-\mathrm{cm}$ trapezoid notch

\subsection{Specimens}

Hollow core concrete brick is made of a sand and cement mixture in a ratio of $6: 1$. The ratio of sand to stone ash in the mixture is $25: 75$, resulted from the preliminary tests to obtain the optimum composition. The composition ratio of the mixtures used is presented in Table 1, and the average compressive strength test results of three mortar specimens are presented in Table 2. The wall specimens are made with a size of $90 \times 45 \mathrm{~cm}^{2}$ for out-of-plane loading and $60 \times 60 \mathrm{~cm}^{2}$ for in-plane loading. The specified details are presented in Table 3 and the wall specimen section can be seen in Figure 2.

Table 1. Mixture composition

\begin{tabular}{|c|c|c|c|c|c|c|c|}
\hline No. & Number & Ratio & $\begin{array}{c}\text { Total weight } \\
(\mathrm{g})\end{array}$ & $\begin{array}{c}\text { Water } \\
(\mathrm{g})\end{array}$ & $\begin{array}{c}\text { Cement } \\
(\mathrm{g})\end{array}$ & $\begin{array}{c}\text { Sand } \\
(\mathrm{g})\end{array}$ & $\begin{array}{c}\text { Stone ash } \\
(\mathrm{g})\end{array}$ \\
\hline 1. & 3 & $100: 0$ & 1343 & 97.82 & 177.86 & 1067.15 & 0 \\
\hline 2. & 3 & $75: 25$ & 1380 & 97.82 & 177.86 & 800.36 & 266.79 \\
\hline 3. & 3 & $60: 40$ & 1380 & 97.82 & 177.86 & 640.29 & 426.86 \\
\hline 4. & 3 & $50: 50$ & 1380 & 97.82 & 177.86 & 533.58 & 533.58 \\
\hline 5. & 3 & $40: 60$ & 1380 & 97.82 & 177.86 & 426.86 & 640.29 \\
\hline 6. & 3 & $25: 75$ & 1380 & 97.82 & 177.86 & 266.79 & 800.36 \\
\hline
\end{tabular}

Table 2. Average compressive strength of three mortar specimen.

\begin{tabular}{|c|c|c|c|}
\hline \multirow{2}{*}{ No } & \multirow{2}{*}{ Ratio } & \multicolumn{2}{|c|}{ Average Compressive Strength (MPa) } \\
\cline { 3 - 4 } & & In 3 days & In 7 days \\
\hline 1. & $100: 0$ & 2.70 & $4.90 \mathrm{c}$. \\
\hline 2. & $75: 25$ & 2.75 & 6.57 \\
\hline 3. & $60: 40$ & 3.75 & 7.70 \\
\hline 4. & $50: 50$ & 4.50 & 8.63 \\
\hline 5. & $40: 60$ & 5.50 & 8.63 \\
\hline 6. & $25: 75$ & 6.15 & 11.43 \\
\hline
\end{tabular}



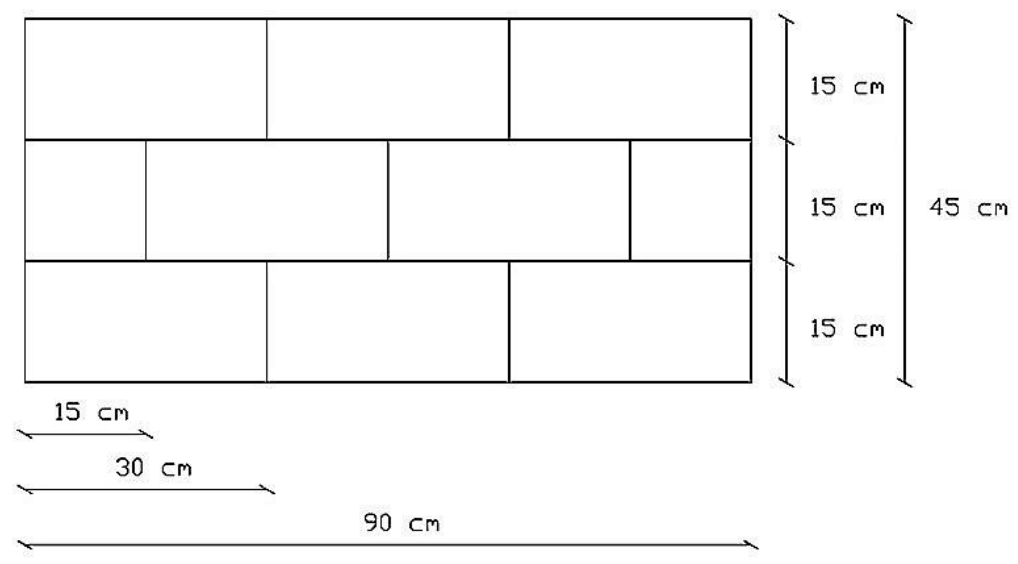

(a)
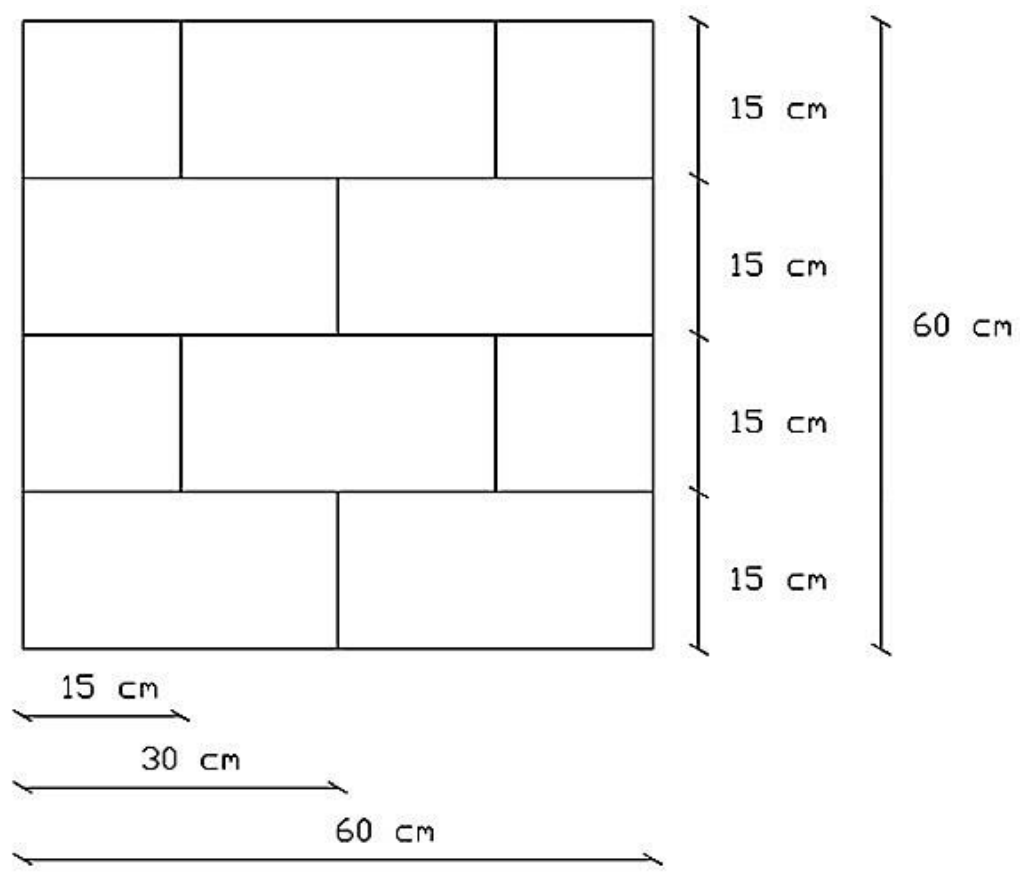

(b)

Fig. 2. Hollow core concrete brick wall sections: (a) for out-of-plane loading, (b) for in-plane loading Table 3. Details of hollow core concrete brick wall.

\begin{tabular}{|c|c|c|c|c|c|}
\hline No & Size $\left(\mathrm{cm}^{2}\right)$ & Loading & Notch model & Notch depth $(\mathrm{cm})$ & Number \\
\hline 1. & \multirow{3}{*}{$90 \times 45$} & \multirow{3}{*}{$\begin{array}{l}\text { Out of plane } \\
\text { loading }\end{array}$} & Square & 2 & 3 \\
\hline 2. & & & Trapezoid & 3 & 3 \\
\hline 3. & & & Trapezoid & 3.5 & 3 \\
\hline 4. & \multirow{3}{*}{$60 \times 60$} & \multirow{3}{*}{$\begin{array}{l}\text { In plane } \\
\text { loading }\end{array}$} & Square & 2 & 3 \\
\hline 5. & & & Trapezoid & 3 & 3 \\
\hline 6. & & & Trapezoid & 3.5 & 3 \\
\hline
\end{tabular}




\subsection{Experimental Procedures}

The experimental procedures refer to the previous study [6]. Hollow core concrete brick is initially made by preparing moulds and a working floor covered with plastic. Next, all materials are weighed and mixed in concrete mixer machines. The mixture is stirred well and then poured mixture into moulds that have been coated with a lubricant and into the middle of which a PVC pipe has been installed. After that, the mixture is allowed to solidify so that there are no air cavities in it. Once the moulds are completely filled up with mixture, the following step is to level out the mould surfaces and hit the surrounding outer part of the mould. The next step is to wait for about 5 minutes before removing the PVC pipes. The process of making the hollow core concrete bricks is illustrated in Figure 3. To obtain hollow core concrete brick wall specimens, three pieces of each brick type are subsequently made by first calculating the requirements for one specimen of hollow core concrete brick. The process of making the specimens of hollow core concrete brick wall can be seen in Figure 4. Measurement of the dimensions and weight of each specimen is then performed and assisting lines are provided to help the researcher define the crack patterns. The flexural strength testing uses two-point loading, as seen in Figure 5.

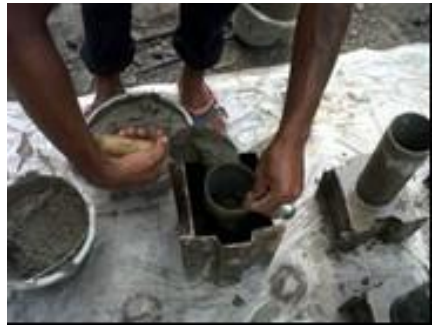

(a)

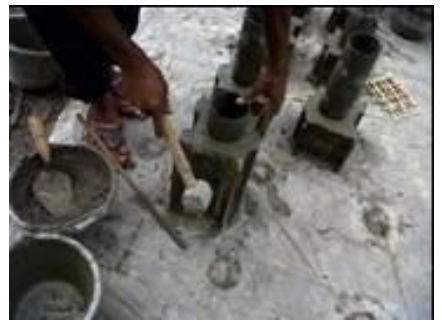

(c)

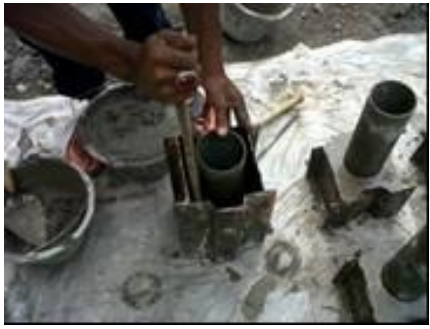

(b)

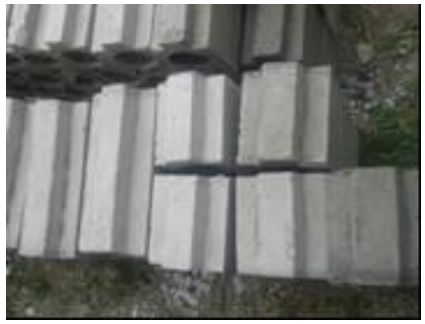

(d)

Fig. 3. Hollow core concrete brick making processes [6]: (a) pouring mixture to the mould, (b) solidifying the mixture (c), hitting the surrounding outer part of the mould, (d) hollow core concrete bricks

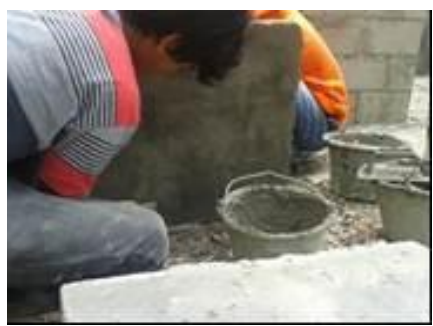

(a)

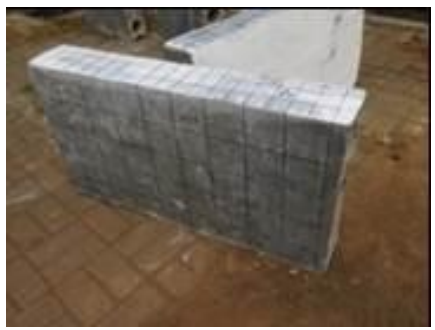

(b)

Fig. 4. Process of making specimens of hollow core concrete brick wall: (a) organizing the hollow concrete bricks, (b) hollow core concrete brick walls 


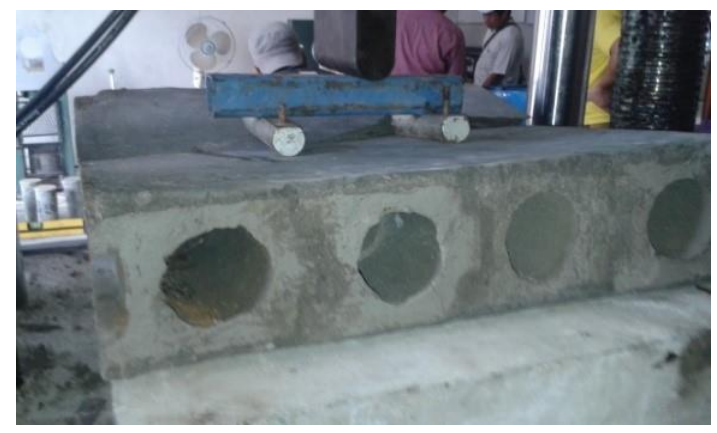

Fig. 5. Flexural strength testing under two-point loading

\section{Results and discussion}

\subsection{Flexural strength}

The results of the tests conducted show that the notch model as the interlocking device influences the connections of the hollow core concrete brick wall. This is indicated by the increasing flexural strength of the hollow core concrete brick wall in various shapes and the notch depth. The square notch shape has a greater influence on the flexural strength of the hollow core concrete brick wall than the trapezoidal notch shape. Due to the square notch shape, the interlocking device mechanism may become more rigid than the notch depth increase yet still maintain its trapezoidal shape. The average flexural strengths of the three tested hollow core concrete brick walls are presented in Table 4.

Table 4. Average flexural strengths of three tested hollow core concrete brick walls

\begin{tabular}{|c|c|c|c|c|c|}
\hline No & Size $\left(\mathrm{cm}^{2}\right)$ & Loading & Notch model & Notch depth $(\mathrm{cm})$ & Flexural strength $\left(\mathrm{kN} / \mathrm{m}^{2}\right)$ \\
\hline 1. & \multirow{4}{*}{$90 \times 45$} & \multirow{4}{*}{$\begin{array}{l}\text { Out of plane } \\
\text { loading }\end{array}$} & Trapezoid [6] & 2 & 185.19 \\
\hline 2. & & & Square & 2 & 212.29 \\
\hline 3. & & & Trapezoid & 2 & 108.55 \\
\hline 4. & & & Trapezoid & 3.5 & 267.64 \\
\hline 5. & \multirow{4}{*}{$60 \times 60$} & \multirow{4}{*}{$\begin{array}{l}\text { In plane } \\
\text { loading }\end{array}$} & Trapezoid [6] & 2 & 120.00 \\
\hline 6. & & & Square & 2 & 330.92 \\
\hline 7. & & & Trapezoid & 3 & 229.63 \\
\hline 8. & & & Trapezoid & 3.5 & 143.79 \\
\hline
\end{tabular}

It is shown that the hollow core concrete brick wall using the 2-cm square notch model has a flexural strength of 212.29 and $330.92 \mathrm{kN} / \mathrm{m}^{2}$, while in the previous tests conducted by Wariyatno et al. [6] on a hollow core concrete brick wall using the 2-cm trapezoid notch model, flexural strengths of 185.19 and $120.00 \mathrm{kN} / \mathrm{m}^{2}$ were obtained under out-of-plane and in-plane loading, respectively. This shows that there are flexural strength increases of 14.64 and $175.77 \%$, respectively, under out-of-plane and in-plane loading. The comparison of the flexural strengths of the hollow core concrete brick walls with variations in notch shape may be seen in Figure 6. 


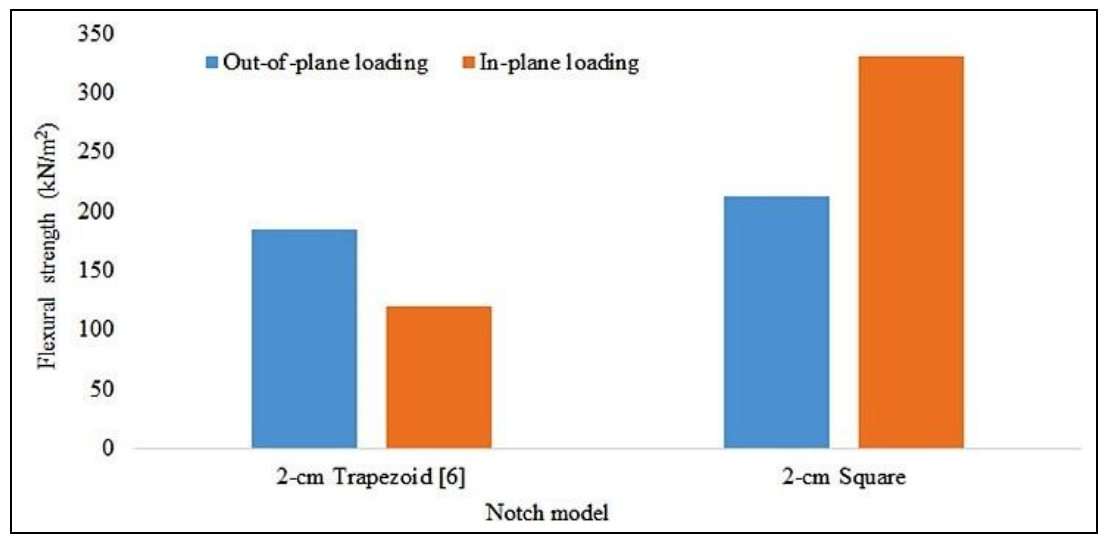

Fig. 6. Flexural strength of hollow core concrete brick wall based on notch shapes

It is also shown that the hollow core concrete brick wall using the 3-cm trapezoidal notch model has flexural strengths of 108.55 and $226.63 \mathrm{kN} / \mathrm{m}^{2}$ under out-of-plane and inplane loading, respectively, while the hollow core concrete brick wall using the $3.5-\mathrm{cm}$ trapezoidal notch model has flexural strengths of 267.75 and $143.79 \mathrm{kN} / \mathrm{m}^{2}$. This shows that the hollow core concrete brick walls using the $3-\mathrm{cm}$ and $3.5-\mathrm{cm}$ trapezoidal notch models have greater flexural strength than the hollow brick wall using the $2-\mathrm{cm}$ trapezoid notch model under in-plane loading. The flexural strength comparison of hollow core concrete brick walls according to variations in notch depth can be seen in Figure 7.

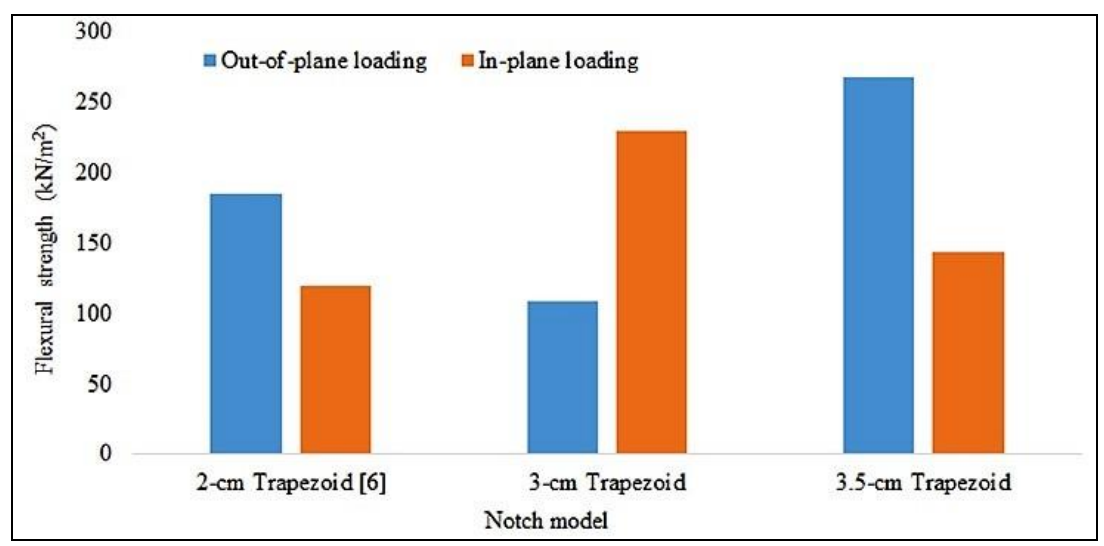

Fig. 7. Flexural strength of hollow core concrete brick walls based on notch depth

\subsection{Collapse patterns}

In the case of the hollow core concrete brick wall using the 2-cm square notch model under out-of-plane loading, the collapse initially starts from the material parts and then propagates to the connections. Meanwhile, the collapse of the hollow brick core concrete wall using the $3-\mathrm{cm}$ trapezoid notch model initially starts from the connections. As the load increases, cracks on the loading surfaces become wider and propagate to the material parts, eventually resulting in fractures. The hollow core concrete brick wall using the $3.5-\mathrm{cm}$ notch model tends to be more bound since it has the greatest notch depth, but the trapezoidal shape is unable to provide sufficient rigidity. The collapse patterns of the hollow core concrete brick wall under out-of-plane loading can be seen in Figure 8. 

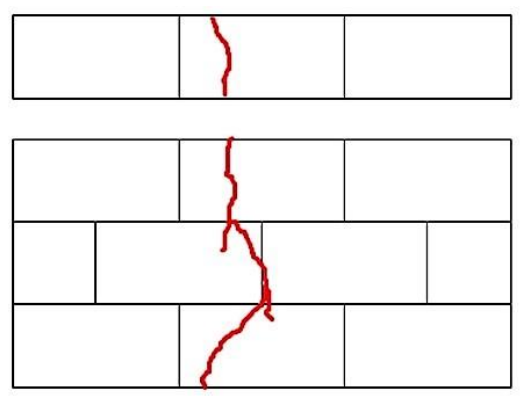

(a)
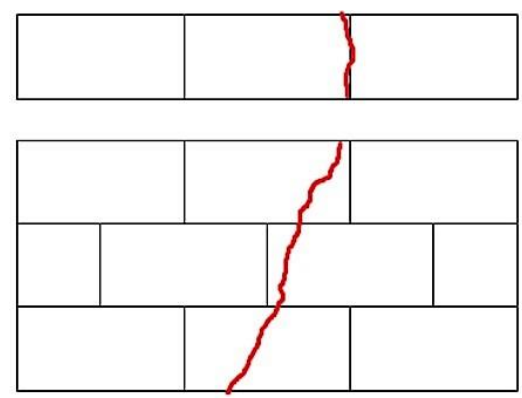

(b)
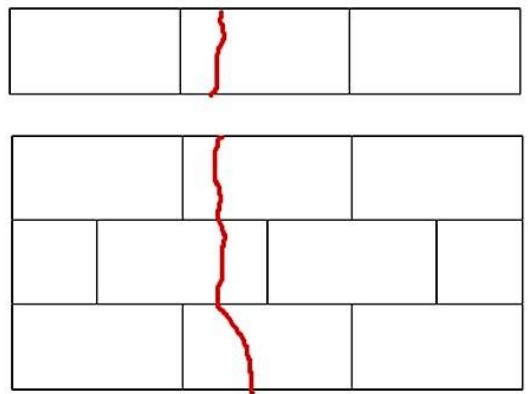

(c)

Fig. 8. The collapse patterns of the hollow core concrete brick wall under out-of-plane loading; (a) 2$\mathrm{cm}$ square notch, (b) $3-\mathrm{cm}$ trapezoidal notch, (c) $3.5-\mathrm{cm}$ trapezoidal notch

The hollow core concrete brick wall using the 2-cm square notch model under in-plane loading initially starts to collapse in the material parts and then the collapse area widens and propagates to the connections. The square notch shape may improve the interlocking mechanism between materials at the connection parts. The collapse of the hollow core concrete brick wall using the $3-\mathrm{cm}$ trapezoid notch model also initially starts in the material. The greater notch depth may influence the bonds between materials, giving a stronger homogenity. Similarly, the hollow brick wall using the $3.5-\mathrm{cm}$ trapezoidal notch model has more stable cracks. The collapse patterns of the hollow core concrete brick wall under in-plane loading can be seen in Figure 9.
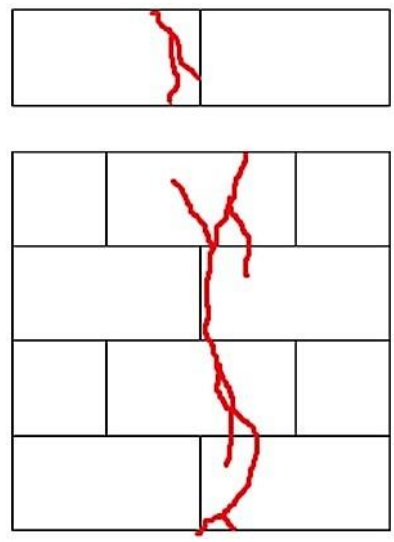

(a)
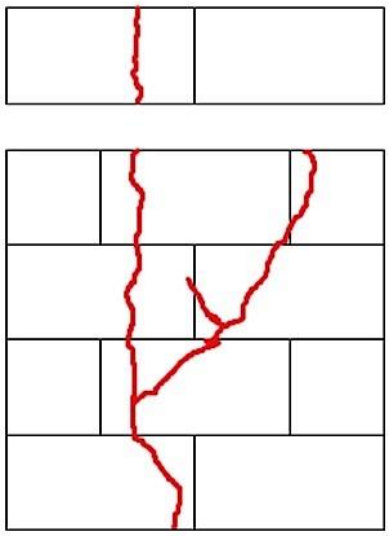

(b) 

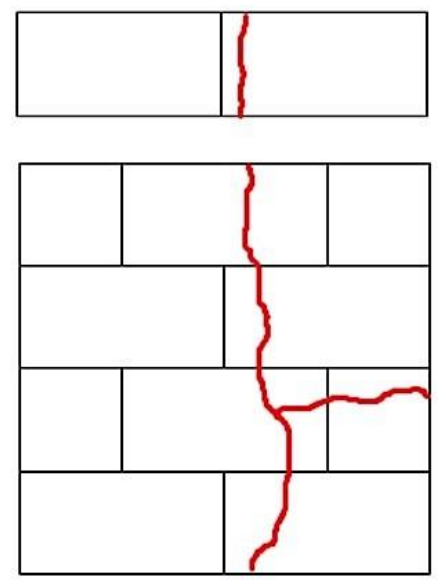

(c)

Fig. 9. The collapse patterns of the hollow core concrete brick wall under in-plane loading: (a) 2-cm square notch, (b) $3-\mathrm{cm}$ trapezoidal notch, (c) $3.5-\mathrm{cm}$ trapezoidal notch.

\section{Conclusion}

From the results of the study conducted, some conclusions are drawn as follows:

a. The flexural strength of hollow core concrete brick wall using the 2-cm square notch model is increased by $14.63 \%$ compared to the one using the $2-\mathrm{cm}$ trapezoidal notch model under the out-of-plane loading.

b. The flexural strength of the hollow core concrete brick wall using the 2-cm square notch model is increased by $175.77 \%$ compared to the one using the $2-\mathrm{cm}$ trapezoidal notch model under in-plane loading.

c. The notch model as an interlocking device influences the connections of the hollow core concrete brick wall. The square notch shape provides a greater influence on the flexural strength of the hollow brick wall than the trapezoidal notch shape.

\section{References}

1. Badan Pusat Statistik, Nilai Konstruksi Yang Diselesaikan Menurut Jenis Pekerjaan (juta rupiah), 2004-2015, Update 17 October 2016, Available from https://www.bps.go.id/linkTabelStatis/view/id/918, (2016)

2. PT Semen Indonesia (Persero) Tbk, 2017, Konsumsi Semen Naik 8 Persen, Update 31 October 2016 (2016), Available from http://bumn.go.id/semenindonesia/berita/2139

3. J. Tanjung, Maidiawati, J. Tek. Sip., 23, 99 (2016)

4. Y. Haryanto, G.H. Sudibyo, F.C.A. Effendi, Procedia Eng., 171, 1025 (2017)

5. Y. Haryanto, B.S. Gan, N.G. Wariyatno, E.W. Indriyari, ARPN JEAS, 12, 4858 (2017)

6. M. Pang, S. Yang, Y. Zhang, Y., Sustainability, 4, 2630 (2012)

7. W. Cao, Y. Zhang, H. Dong, Z. Zhou, Q. Qiao, Materials, 7, 5934 (2014)

8. N.G. Wariyatno, Y. Haryanto, Sumiyanto, J. Il. Tek. Sip., 21, 136 (2017) 